\title{
Model taman literasi berbasis ecobrick
}

\author{
Edi Suhendri $^{1}$, Zulfan Saam ${ }^{2}$, Imam Suprayogi ${ }^{3}$, Daviq Chairilsyah ${ }^{4}$ \\ ${ }^{1}$ Mahasiswa Program Pascasarjana Ilmu Lingkungan Universitas Riau \\ ${ }^{2,3,4}$ Dosen Program Pascasarjana Ilmu Lingkungan Universitas Riau \\ *Correspondent email: suhendrie792@gmail.com
}

\section{Diterima: 19 Agustus 2021| Disetujui: 30 Oktober 2021 | Diterbitkan: 31 Oktober 2021}

\begin{abstract}
Making literacy parks in schools is a very important means of improving the reading culture in students. The development of a green literacy park must pay attention to environmental sustainability aspects in the form of saving energy, water, materials and land suitability, in such a way as to reduce carbon emissions and maintain the availability of natural resources. Ecobrick is a solution that can be applied in schools so that plastic waste, especially soft plastic produced in schools, can be used as something useful, namely being used as a literacy park. This research method is descriptive qualitative. Collecting data is obtained through questionnaires, observation and documentation. The research was conducted at Junior High School Pekanbaru. The results showed that the amount of waste production for Junior High Schools Pekanbaru City which consists of 45 schools with a total of 30,639 students in 2020 the average production of plastic waste is 15 grams/day. Meanwhile, the total production of plastic waste at Junior High Schools Pekanbaru City is $456,620 \mathrm{~kg} /$ day. The construction of an eco-friendly ecobrickbased literacy park is one of the solutions in handling plastic waste in schools, by using an ecobrick of 600 $\mathrm{ml}$ aqua bottles, so the construction of an $8 \mathrm{~m} \times 6 \mathrm{~m}$ park $\left(48 \mathrm{~m}^{2}\right)$ requires 10,800 ecobricks. Where in $1 \mathrm{~m}^{2}$ it takes 225 bottles or the equivalent of 45,000 grams of waste. So that for a garden with an area $48 \mathrm{~m}^{2}$ can degrade plastic waste 2,160,000 grams (2,160 tons) of garbage.
\end{abstract}

Keywords: Model; Garden; Literacy; Ecobrick

Total produksi sampah Kota Pekanbaru yang masuk ke TPA setiap hari mencapai 1.100 ton, sampah tersebut berasal sampah yang dihasilkan oleh masyarakat, pasar, kantor dan sekolah (DLHK, 2020). Pengelolaan sampah di sekolah membutuhkan perhatian serius karena sebagian besar populasinya adalah anak-anak (warga belajar) tidak menutup kemungkinan pengelolaan sampah yang dilakukan belum optimal. Namun sampah di sekolah dapat dipakai sebagai media pembelajaran bagi peserta didik. Salah satu parameter sekolah yang baik dalam pengelolaan sampah adalah sekolah yang berwawasan lingkungan.

Untuk mengurangi sampah plastik di sekolah, kepala sekolah mengeluarkan kebijakan agar kantin sekolah tidak menjual makanan dan minuman yang berkemasan plastik. Hasil survey dan wawancara peneliti dengan DLHK Kota Pekanbaru, dari 178 Sekolah Menengah Pertama (SMP) Negeri dan Swasta termasuk Madrasah Tsanawiyah (MTS) Negeri dan swasta di Kota Pekanbaru sebanyak 40 (22,5\%) Sekolah yang memiliki kebijakan kantin sekolah dilarang berjualan makanan dan minuman yang berkemasan plsastik sedangkan selebihnya 138 (77,5\%) sekolah tidak melarang kantin sekolah untuk berjualan makanan/minuman yang berkemasan plastik (DLHK, 2020).

Banyak sekolah-sekolah menerapkan aturan bahwa kantin dilarang menjual makanan dan minuman yang berkemasan plastik baik makanan olahan pabrik maupun makanan olahan rumah tangga. Meskipun sekolah sudah bisa menertibkan aturan larangan tersebut akan tetapi masih banyak anak-anak sekolah yang membeli dan membawa makan yang berkemasan plastik baik yang dibelinya disekolah maupun yang dibawanya dari rumah. Oleh karena itu sampah sekolah harus bisa dikelola dengan baik menjadi salah satu sarana seperti taman literasi.

\section{METODE PENELITIAN}

Penelitian dilakukan di Sekolah Menengah Pertama Negeri (SMPN) Kota Pekanbaru. Metodologi penelitian adalah deskriptif kualitatif. Pengumpulan data dilakukan dengan menggunakan instrumen angket, observasi langsung, dan dokumentasi. Angket disebarkan kepada guru dan peserta didik untuk mengetahui pemahaman tentang taman literasi berbasis ecobrick dan pengelolaan sampah plastik, kebijakan sekolah, sikap dan perilaku. Observasi bertujuan untuk mengamati secara langsung kondisi sekolah, program sekolah dan tatanan lingkungan sekolah. Dokumentasi sebagai data pendukung untuk memperkuat bukti keterlibatan sekolah dalam kepedulian dan pengelolaan lingkugan hidup. Data akan dijelaskan secara deskriptif kualitatif. 


\section{HASIL DAN PEMBAHASAN}

Dari hasil survey peneliti, jumlah produksi sampah untuk Sekolah Menengah Pertama (SMP) Negeri Kota Pekanbaru yang terdiri dari 45 sekolah dengan jumlah siswa 30.639 pada tahun 2020 produksi sampah plastik rata-rata persiswa $15 \mathrm{gram} /$ hari. Sedangkan total produksi sampah plastik di SMP Negeri Kota Pekanbaru sebanyak 456,620 kg/hari. Hampir setengah ton produksi sampah plsatik yang berasal dari sekolah. Oleh kerena itu karena banyaknya sampah plastik yang berasal dari sekolah, maka diperlukan penanganan sampah yang baik agar tidak menjadi sumber pencemaran.

Ecobrick merupakan salah satu solusi yang bisa diterapkan di sekolah agar limbah plastik khususnya plastik lunak seperti tas kresek, plastik bungkusan makanan ringan dan plastik minuman sachet yang merupakan bahan limbah dapat menjadi sesuatu yang bermanfaat. Ecobrick berasal dari kata Eco (lingkungan) dan Brick (bata) yang berarti bata ringan yang ramah lingkungan. Ecobrick adalah bata ramah lingkungan, yaitu dengan memanfaatkan sampah plastik yang dipadatkan sedemikian rupa dalam suatu wadah tertentu (Fatchurrahman. 2018). Ecobrick diprakarsai oleh Russell Maier dan Ani Himawati dari Global Ecobrick Alliance (GEA) yang merupakan pelopor gerakan Ecobrick di dunia. Botol minuman bekas yang berbahan plastik PET bisa didaur ulang menjadi biji plastik. Demikian juga halnya dengan kaleng minuman bekas yang berbahan logam. Sampah jenis plastik dipilah, dikumpulkan untuk kemudian dijual. Peserta didik di sekolah dapat berkreasi merangkainya menjadi barang kerajinan atau hiasan dinding.

Untuk mengatasi berbagai permasalahan diperlukan teknik pengelolaan yang baik, khususnya untuk sampah plastik tidak perlu kita berpikiran bagaimana cara untuk menguraikannya akan tetapi kita buat sampah plastik bertambah panjang usianya. Melalui teknik ecobrick sampah plastik akan sangat berguna, sampah-sampah tersebut diubah menjadi bagian-bagian kecil (brick) lalu dimasukkan ke dalam botol plastik kemudian dengan bantuan kayu, sampah tersebut dimampatkan agar tidak ada ruang kosong pada botol tersebut. Melalui teknik ecobrick, sampah-sampah plastik akan tersimpan dan terjaga di dalam botol sehingga sampah tersebut tidak perlu dibakar atau dibiarkan menggunung dan tertimbun. Fungsi dari ecobrick bukan untuk menghancurkan sampah plastik, melainkan untuk memperpanjang usia plastik-plastik tersebut dan mengolahnya menjadi sesuatu yang berguna, yang bisa dipergunakan bagi kepentingan manusia pada umumnya (Asih, 2018). Untuk pembuatan ecobrick maka bisa dikatakan untuk membuat ecobrick tidak sulit, hanya memerlukan ketelatenan dan sedikit usaha. Secara umum langkah-langkah membuat ecobrick adalah sebagai berikut : 1) Mengumpulkan botol-botol plastik bekas, seperti botol bekas kemasan minuman (misalnya air mineral), botol bekas kemasan minyak goreng dan lain sebagainya. Kemudian mencucinya hingga bersih, lalu dikeringkan; 2) Mengumpulkan berbagai macam kemasan plastik, seperti kemasan mie instan, minuman-minuman instan, plastik pembungkus, tas plastik dan sebagainya. Harus dipastikan plastik-plastik tersebut bebas dari segala jenis makanan (yang tersisa didalamnya), dalam keadaan kering dan tidak tercampur oleh bahan lain (klip, benang, kertas dan sebagainya); 3) Memasukkan segala jenis plastik yang ada di poin ke 2 ke dalam botol-botol plastik pada poin ke 1 ; 4) Tidak boleh tercampur dengan kertas, kaca, logam, benda-benda yang tajam dan bahan-bahan lain selain plastik; 5) Bahan-bahan plastik yang dimasukkan ke dalam botol plastik harus dimampatkan hingga sangat padat dan mengisi seluruh ruangan dalam botol plastiknya; 6) Cara memadatkannya bisa dengan menggunakan alat yang terbuat dari bambu atau kayu (seperti tongkat bambu atau kayu); 7) Jika ingin membuat sesuatu dengan hasil ecobrick ini, misalnya membuat meja, kursi, atau benda-benda lain, maka bisa menggunakan botol-botol yang berukuran sama, atau bahkan dari jenis dan merk yang sama, sehingga memudahkan penyusunan; 8) Jika menginginkan hasil yang berwarna-warni, maka plastik-plastik kemasan yang disusun didalamnya bisa diatur sedemikian rupa sehingga menghasilkan warna sesuai yang diinginkan. Bisa juga dengan cara membungkus botol plastik dengan cellophone/pita perekat yang berwarna; 9) Setelah semua botol plastik diisi dengan kemasan-kemasan plastik hingga padat, maka botolbotol plastik tersebut siap disusun dan digabungkan menjadi benda lain, seperti meja, kursi, bahkan dinding dan atau lantai panggung, pembatas ruangan dan banyak lagi lainnya.

Botol ecobrick bisa dimanfaatkan untuk pembuatan berbagai macam bangunan di sekolah seperti bangku taman, meja taman, pot bunga dan panggung, sehingga penggunaan batu bata bisa dikurangi dan biaya material bisa lebih hemat. Hingga saat ini belum ada Sekolah Menengah Pertama (SMP) yang memanfaatkan ecobrick untuk dijadikan taman literasi tempat anak-anak istirahat sambil bersantai sambil membaca buku.

Pembuatan taman literasi di sekolah merupakan sarana yang sangat penting untuk meningkatkan pembudayaan kegemaran membaca pada perserta didik. Pada taman literasi yang nyaman hendaknya menyediakan dan memberikan layanan di bidang bahan bacaan, berupa: buku, majalah, tabloid, koran, komik, dan bahan multi media lain, yang dilengkapi dengan ruangan untuk membaca, diskusi, bedah buku, menulis, dan kegiatan literasi lainnya, dan didukung oleh pengelola yang berperan sebagai motivator (Direktur Jenderal Pendidikan Anak Usia Dini, Nonformal, 2012). Adapun desain taman literasi berbasis ecobrick yang direncanakan seperti yang ditunjukkan pada gambar berikut: 


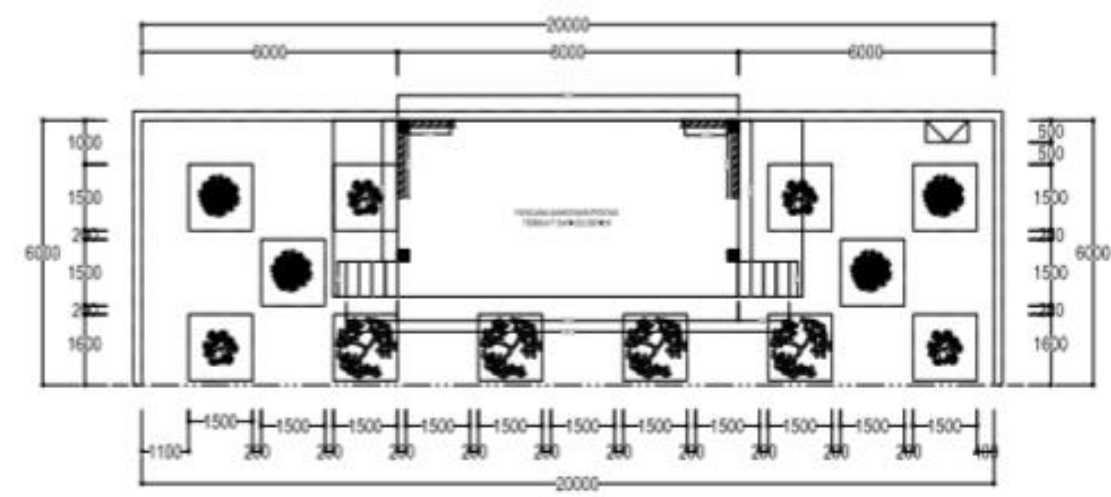

Gambar 1. Model Taman Literasi ecobrick

Pembangunan desain taman literasi berbasis ecobrick seperti pada gambar di atas yang ramah lingkungan harus menggunakan sumber daya yang tersedia dengan memanfaatkan barang-barang bekas yang dihasilkan di lingkungan sekolah untuk mengurangi masalah pencemaran sampah. Pemanfaatan ecobrick menjadi taman literasi merupakan satu solusi untuk mendegradasi sampah. Taman terasi yang berbasis ecobrick dalam penelitian ini berukuran $8 \mathrm{~m} \times 4 \mathrm{~m}\left(\right.$ luas $48 \mathrm{~m}^{2}$ ). Dengan menggunakan ecobrick botol aqua yang ukuran $600 \mathrm{ml}$ untuk pembangunan taman $8 \mathrm{~m}$ x $6 \mathrm{~m}$ membutuhkan 10.800 botol ecobrick. Dimana dalam $1 \mathrm{~m}^{2}$ dibutuhkan 225 botol atau setara dengan 45.000 gram (45kg) sampah. Sehingga untuk taman dengan ukuran luas $48 \mathrm{~m}^{2}$ dibutuhkan 2.160 .000 gram (2,160 ton) sampah plastik. Dengan demikian jika satu sekolah memiliki taman literasi dengan luas 48 meter persegi maka jumlah sampah plastik yang bisa tertampung lebih 2, 16 ton.

Dengan adanya taman literasi berbasis ecobrick maka membudayakan siswa untuk gemar membaca, sehingga taman literasi juga merupakan tempat atau ruang yang disediakan untuk menyimpan, memelihara, menggunakan koleksi buku, majalah, koran, multi media lain untuk dibaca, dipelajari, dibicarakan, dan dimanfaatkan oleh masyarakat secara perseorangan, kelompok atau kelembagaan (Direktorat Jendral Pendidikan Luar Sekolah, 2006). Taman literasi sekolah adalah suatu lembaga yang menyediakan bahan bacaan yang dibutuhkan oleh para pelajar, sebagai tempat penyelengaraan pembinaan kemampuan membaca dan belajar, sekaligus sebagai tempat untuk mendapatkan informasi bagi para pelajar yang berada di sekitar lokasi dari Taman baca pelajar tersebut (Wiji Suwarno, 2010)

Hal ini sejalan dengan pendapat Encang Saepudin dalam tingkat budaya literasi yang menyatakan bahwa, berseminya budaya literasi adalah kebiasaan membaca, sedangkan kebiasaan membaca terpelihara dengan tersedianya bahan bacaan yang baik, menarik, memadai, baik jenis, jumlah maupun mutunya. Inilah sebuah formula yang secara ringkas untuk mengembangkan minat dan budaya baca (Saepudin, 2016).

Pembangunan taman literasi sekolah dengan menggunakan ecobrick ini selain membantu dalam penyelamatan lingkungan, juga sangat menguntungkan jika ditinjau dari sisi ekonomi. Dimana sekolah tidak terlalu besar mengeluarkan dana untuk pembangunan. Jika ditinjau dipasaran, harga 1 botol ecobrick sekitar Rp. 1.700,- maka untuk pembangunan taman $48 \mathrm{~m}^{2}$ sudah menghemat biaya sebesar Rp.18.360.000,- (10.800 botol x Rp.1.700).

Pembangunan taman literasi yang ramah lingkungan harus menggunakan konsep green building yakni bangunan yang sejak dimulai dalam tahap perencanaan, pembangunan, pengoprasian hingga dalam operasional pemeliharaannya memperhatikan aspek-aspek dalam melindungi, menghemat, mengurangi penggunaan sumber daya alam, menjaga mutu dari kualitas udara di dalam ruangan, dan memperhatikan kesehatan penghuninya yang semua berpegang pada kaidah bersinambungan.

Pembangunan taman literasi yang hijau harus memperhatikan aspek keberlanjutan lingkungan berupa penghematan energi, air, material dan kesesuaian lahan, sedemikian rupa sehingga menurunkan emisi karbon dan menjaga ketersediaan sumber daya alam.

Pembangunan taman literasi yang ramah lingkungan menggunakan konsep eco building yang merupakan salah satu alternatif untuk pembangunan yang ramah lingkungan. Eco building (bangunan hijau) adalah bangunan yang didesain khusus dengan tema yang ramah lingkungan, hemat energi, layout sederhana tapi tidak membosankan, kualitasnya bermutu, dan material yang ramah lingkungan. Eco building lebih dimaksudkan pada bentuk fisik bangunan yang berwawasan lingkungan. Untuk mendukung konsep eco building dalam pembangunan taman literasi maka penggunaan ecobrick merupakan material yang sangat cocok untuk digunakan, selain itu ecobrick merupakan solusi cerdas dan kreatif untuk mengatasi sampah plastik. Sampah plastik bisa diubah menjadi benda-benda yang berguna, ecobrick merupakan salah satu solusi untuk mengurangi pencemaran dan racun yang ditimbulkan oleh sampah plastik (Sekartaji Suminto, 2017). 


\section{KESIMPULAN}

Pembangunan taman literasi sekolah dengan ecobrick sangat membantu dalam mendegradasi sampah plastik yang dihasilkan sekolah. Selain proses pembuatannya mudah, ecobrick yang merupakan upaya kreatif untuk mengelola sampah plastik menjadi benda-benda yang berguna, mengurangi pencemaran dan racun yang ditimbulkan oleh sampah plastik. Fungsinya bukan untuk menghancurkan sampah plastik, melainkan untuk memperpanjang usia plastik-plastik tersebut dan mengolahnya menjadi sesuatu yang berguna, yang bisa digunakan bagi kepentingan manusia pada umumnya.

\section{DAFTAR PUSTAKA}

Asih, Hayati Mukti \& Fitriani, Syifa. (2018). Penyusunan Standard Operating Procedure (SOP) Produksi Produk Inovasi Ecobrick. Jurnal Ilmiah Teknik Industri, 7(2), 144-150.

Direktorat Pendidikan Masyarakat, (2006). Pedoman Pengelolaan Taman Bacaan Masyarakat. Jakarta: Direktorat Jendral Pendidikan Luar Sekolah. h.23

Direktur Jenderal Pendidikan Anak Usia Dini, Nonformal, dan I. (2012). Petunjuk Teknis Pengajuan dan Pengelolaan Taman Bacaan Masyarakat (TBM) Ruang Publik. Jakarta: Kementerian Pendidikan dan Kebudayaan.

Fatchurrahman. (2018). Manajemen Pengelolaan Sampah Berkelanjutan Melalui Inovasi "Ecobrick" Oleh Pemerintah Kota Yogyakarta. Https://Www.Researchgate.Net/Publication/325284392. Manajemen Pengelolaan Sampah Berkelanjutan Melalui Inovasi Ecobrick Oleh Pemerintah Kota Yogyakarta. Di akses 24 Agustus 2020.

Saepudin, E. (2016). Tingkat Budaya Membaca Masyarakat (Studi Kasus Pada Masyarakat Di Kabupaten Bandung). Jurnal Kajian Informasi dan Perpustakaan, 3(2), 276.

Suminto, Sekartaji. (2017). Ecobrick Solusi Cerdas dan Kreatif untuk Mengatasi Sampah Pelastik. Productum: Jurnal Desain Produk (Pengetahuan dan Perancangan Produk) 3 (1):26-34.

Wiji Suwarno, (2010). Pengetahuan Dasar Kepustakaan. Bogor: Ghalia Indonesia, 2010), h. 31. 